\title{
Nonabsorbable suture granuloma mimicking ovarian cancer recurrence at combined positron emission tomography/computed tomography evaluation: a case report
}

\author{
Ludovica Imperiale ${ }^{\dagger}$, Claudia Marchetti ${ }^{* \dagger}$, Laura Salerno, Roberta ladarola, Carlotta Bracchi, Laura Vertechy, \\ Lucia di Francesco, Angela Musella, Elisa Bevilacqua, Primo Pennesi, Innocenza Palaia and Pierluigi Benedetti Panici
}

\begin{abstract}
Introduction: This is the first case of suture granuloma mimicking isolated ovarian cancer relapse. Only six analogous cases have been previously reported in other malignancies.

Case presentation: We report the case of a 44-year-old Caucasian woman with partially platinum-sensitive ovarian cancer in which radiological features, including computed tomography and combined ${ }^{18} \mathrm{~F}$-fluorodeoxyglucose-positron emission tomography/computed tomography, were strongly suggestive of isolated cancer relapse in her right subdiaphragmatic region. Laparoscopic examination resulted negative, but was not completely suitable due to widespread adhesive syndrome. The laparotomy for secondary cytoreductive surgery and biopsy of the suspected area showed inflammatory granuloma caused by nonabsorbable propylene suture, without evidence of neoplastic cells. Moreover, unexpected peritoneal carcinosis was found.

Conclusions: This evidence suggests that clinical details about previous surgical procedures are necessary for adequate interpretation. Although much progress has been made in imaging techniques, especially in the promising field of combined ${ }^{18} \mathrm{~F}$-fluorodeoxyglucose positron emission tomography/computed tomography, these procedures should be still thoroughly investigated in order to promptly rule out tumor recurrence and avoid unnecessary surgery.
\end{abstract}

Keywords: Cancer, Diagnosis, Foreign body, Surgery

\section{Introduction}

Despite aggressive and curative initial treatment, the majority of patients with ovarian cancer manifest persistent disease or develop fatal recurrence. The liver is the fourth most common site of metastasis in recurrent ovarian cancer (ROC) [1]: clinical data from living patients have shown an incidence of hepatic metastasis of approximately $9.4 \%[2]$. Currently available therapeutic options for recurrent patients are second-line chemotherapy and secondary cytoreductive surgery (SCR); these options are reserved to selected patients in whom the number

\footnotetext{
* Correspondence: clamarchetti@libero.it

${ }^{\dagger}$ Equal contributors

Department of Gynecological and Obstetrical Sciences and Urological

Sciences, Sapienza University of Rome, Via del Policlinico, 155, 00161 Rome, Italy
}

\section{() Biomed Central}

of metastatic sites is limited and complete surgical resection is an expected outcome $[3,4]$.

The occurrence of granuloma after surgery with nonabsorbable surgical suture has been rarely described after bowel, lung and pharynx oncologic surgeries [5-7]; in all these cases granuloma was confused with cancer recurrence and patients received unnecessary surgeries.

To the best of our knowledge this is the first case of nonabsorbable suture granuloma mimicking ovarian cancer recurrence after primary debulking surgery for ovarian cancer.

We report the case of a woman with partially platinumsensitive ovarian cancer in which radiological features, including computed tomography $(\mathrm{CT})$ and combined ${ }^{18} \mathrm{~F}$-fluorodeoxyglucose $\left({ }^{18} \mathrm{~F}\right.$-FDG $)$ positron emission 
tomography/CT (PET/CT), were strongly suggestive of isolated cancer relapse in her right subdiaphragmatic region.

\section{Case presentation}

A 44-year-old Caucasian woman was admitted to our institution because of adnexal complex masses, ascites and a carbohydrate antigen (CA)-125 value of $876 \mathrm{U} / \mathrm{mL}$ (normal range 0 to $35 \mathrm{U} / \mathrm{mL}$ ).

Apart from a previous caesarean section, her gynecologic history was uneventful. She underwent laparoscopic evaluation before attempting cytoreductive surgery; she was considered not eligible for primary debulking surgery because of mesenterial involvement and diffuse peritoneal carcinosis with extension to her upper abdomen. Biopsies documented a moderately differentiated papillary ovarian carcinoma at histological findings; according to FIGO (International Federation of Gynecology and Obstetrics) staging it corresponded to IIIC final stage. After three courses of neoadjuvant chemotherapy based on a standard tri-weekly carboplatin and paclitaxel schedule, she achieved a partial clinical response and underwent interval debulking surgery with residual tumor smaller than $0.5 \mathrm{~cm}$. Consequently, she completed the chemotherapy administration receiving three more cycles of adjuvant treatment (carboplatin and paclitaxel).

Further follow-ups were negative for the next 8 months, when a rise of CA-125 to $201 \mathrm{U} / \mathrm{mL}$ was documented. Laboratory data from liver functions tests were unremarkable; no predisposing factors for hepatic cirrhosis, steatohepatitis or dysmetabolic diseases were identified.

She was submitted to an abdominopelvic CT scan (Figure 1) which showed a hyperdense lesion in her right subdiaphragmatic region and a plaque thickening of her diaphragmatic dome, without evidence of peritoneal carcinosis. Taking into account her clinical condition and the isolated area of recurrence considered, she was judged eligible for SCR. In order to achieve a more accurate presurgical assessment a whole-body PET/CT (Figure 2) was performed, showing high metabolic uptake with standardized uptake value (SUV) up to 4.2 in the suspected area, without evidence of other sites of disease.

She underwent surgery. The laparoscopic examination resulted negative, but was not completely reliable due to severe adhesive syndrome. A laparotomy biopsy of the area situated in her right subdiaphragmatic region, over her hepatic dome was performed. A frozen section revealed an inflammatory granuloma probably derived from a propylene stitch applied at the time of the interval debulking surgery (Figure 3). Furthermore an unexpected diffuse peritoneal carcinosis, extended to her entire abdominal cavity but without involvement of her upper abdomen, was identified and multiple biopsies were carried out.

Definitive histological findings confirmed that the subdiaphragmatic lesion was an inflammatory granuloma,

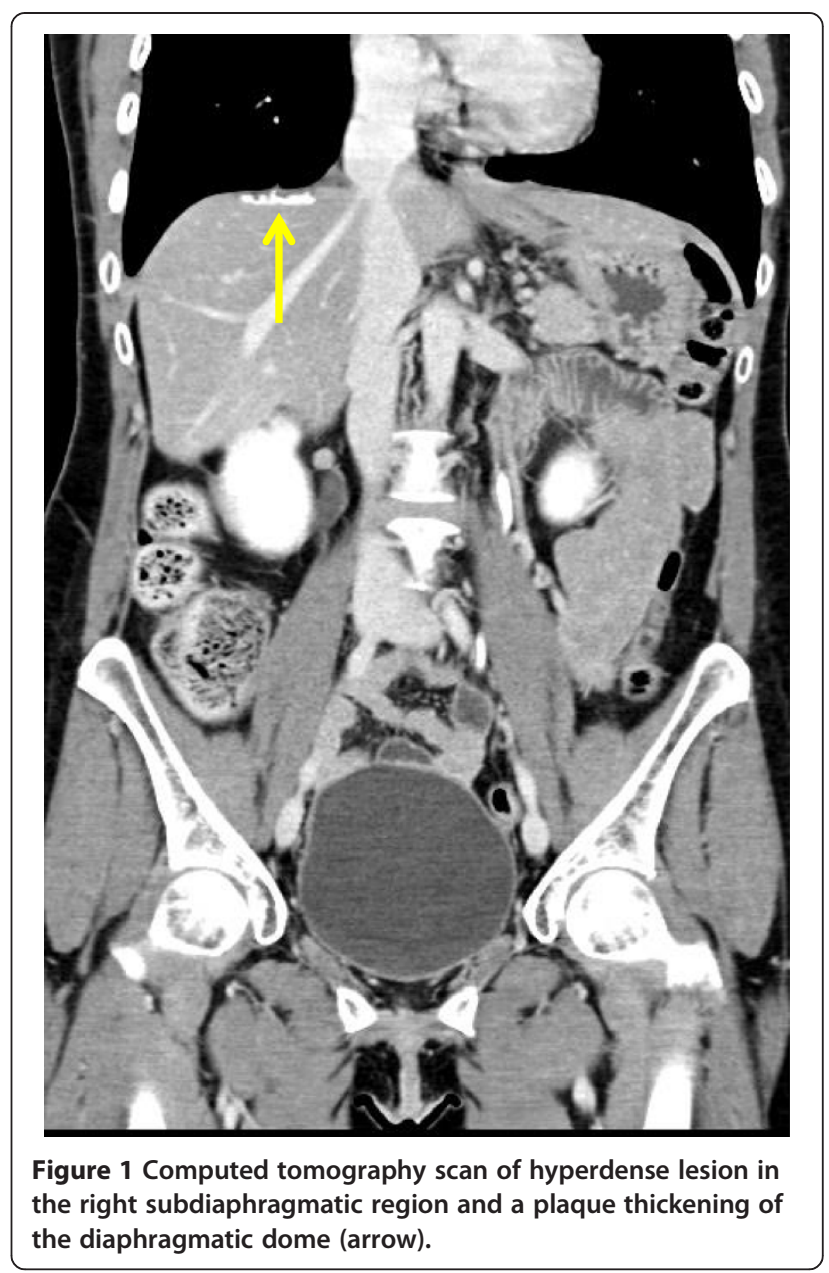

characterized by epithelioid histiocytes and giant cells, with lymphocyte infiltration, around a nonabsorbable propylene suture derived from previous surgery, while other biopsies were found to be sites of relapse.

After surgery she was submitted to second-line chemotherapy based on carboplatin and Caelyx ${ }^{\odot}$ (doxorubicin hydrochloride) and she is now under third-line chemotherapeutic treatment still with persistent evidence of disease.

\section{Discussion}

The role of cytoreduction in ROC is still controversial; in this setting, our policy is directed to perform surgery when one or at most two relapses are detected. This strategy, even if not standardized, is supported by the evidence of improved survival outcomes reported in the literature $[3,8]$. Nevertheless, we are waiting for the results of the Desktop III trial, which will definitively clarify the effectiveness of such an approach.

This case shows that a $3 \mathrm{~cm}$ right subdiaphragmatic lesion was initially characterized at CT and PET/CT imaging as an isolated ovarian cancer relapse. Unexpectedly, the lesion was a nonabsorbable propylene suture granuloma at final 


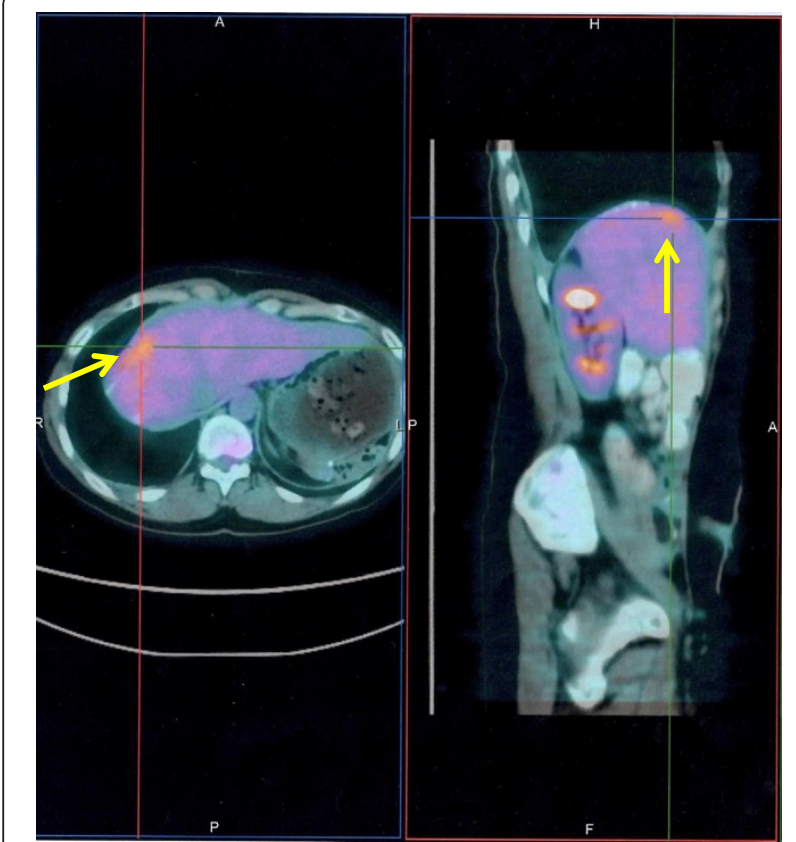

Figure 2 Positron emission tomography/computed tomography scan showing isolated high metabolic uptake (SUV: 4.2) in the right subdiaphragmatic region (arrows).

histologic report and unknown peritoneal carcinosis was found at laparotomy as well. The involvement of the diaphragmatic region, especially the right hemidiaphragm [9], occurs in approximately more than half of the patients with advanced ovarian cancer. Therefore anatomical, surgical and radiological knowledge of this area should be improved when treating ovarian cancer disease. In recent years, many efforts have been made by the gynecologic oncology community to underline the importance of radical diaphragmatic surgery after liver mobilization in order to completely remove the neoplastic implants and improve survival; however, this kind of surgery is burdened by higher perioperative complications $[10,11]$.

The occurrence of granuloma after surgery with nonabsorbable surgical suture has been rarely described, and it usually occurs with the use of silk suture (Table 1) [5-7]; furthermore it has never been associated with ovarian cancer surgery and with the application of propylene suture (Table 1).

In this case the patient developed a late onset granuloma from nonabsorbable propylene suture, 11 months after primary surgery, without any concomitant symptoms and, of note, with previous negative radiological examinations. A suture granuloma is the aseptic fibrinous response to the inflammatory reaction induced by suture antigenicity and/or by the exacerbation of suture bacterial infection, occurring during primary surgery $[6,12]$. On pathological examination it is characterized by an accumulation of epithelioid histiocytes and multinucleated giant cells, which typically surround the foreign bodies. In this case, we can suppose that her clinical and immunologic deteriorations, probably related to concomitant disease recurrence, led to the granuloma formation.

The false-positive result on PET/CT scan in our patient is probably the consequence of this localized inflammation process, that might impair the accuracy of the method [6], mimicking malignant tissue glucose uptake in a PET scan.

The second disappointing radiological finding in this case is the absence of peritoneal carcinosis, by both $\mathrm{CT}$ and PET/CT scans. An early and accurate diagnosis appears to be a fundamental part of the treatment, especially if SCR is taken into consideration. The best approach for preoperative radiological assessment of ROC is still

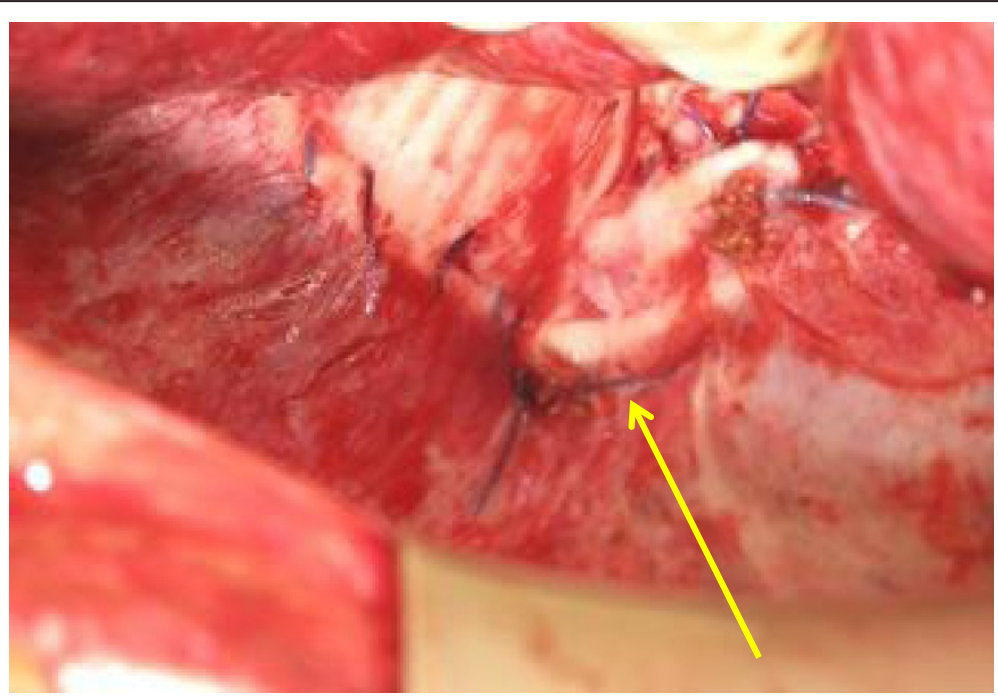

Figure 3 Granuloma from propylene stitch suture (arrow) applied at the time of the interval debulking surgery. 
Table 1 Cases of granuloma after surgery with nonabsorbable surgical suture reported in the literature

\begin{tabular}{|c|c|c|c|c|c|c|}
\hline Reference & Primary diagnosis & Site of FDG accumulation & $\begin{array}{l}\text { Diagnostic } \\
\text { device }\end{array}$ & $\begin{array}{l}\text { SUV } \\
\max \end{array}$ & Histology & $\begin{array}{l}\text { Type of material } \\
\text { of suture }\end{array}$ \\
\hline \multirow[t]{2}{*}{ Lim et al. [5] } & Distal sigmoid colon cancer & Mesentery-mesenteric vein & PET & 3.9 & $\begin{array}{l}\text { Extensive fibrosis with focal } \\
\text { giant cell reaction }\end{array}$ & Silk \\
\hline & Colorectal cancer & $\begin{array}{l}\text { Peritoneum within the } \\
\text { small bowel mesentery }\end{array}$ & PET & 3.4 & $\begin{array}{l}\text { Reactive lymphoid hyperplasia, } \\
\text { fibrosis }\end{array}$ & Silk \\
\hline \multirow[t]{2}{*}{ Yüksel et al. [6] } & Lung cancer & Right upper lobe (lung) & PET & 3.5 & $\begin{array}{l}\text { Strands of nonabsorbable heavy } \\
\text { suture material }\end{array}$ & Silk \\
\hline & Lung cancer & Right lower lobe (lung) & PET & 3.5 & $\begin{array}{l}\text { Inflammatory nodule at the site } \\
\text { of prior suturing }\end{array}$ & Silk \\
\hline \multirow[t]{2}{*}{ Kikuchi et al. [7] } & $\begin{array}{l}\text { Hypopharyngeal squamous } \\
\text { cell carcinoma }\end{array}$ & Prevertebral region & PET & 6.0 & $\begin{array}{l}\text { Epithelioid cells around the } \\
\text { silk suture }\end{array}$ & Silk \\
\hline & $\begin{array}{l}\text { Oropharyngeal squamous } \\
\text { cell carcinoma }\end{array}$ & Left axilla & PET & 4.3 & Giant cells around the silk & Silk \\
\hline
\end{tabular}

Abbreviations: FDG fluorodeoxyglucose, PET positron emission tomography, SUV standardized uptake value.

under investigation, but combined PET/CT has recently gained increasing attention $[13,14]$, with encouraging rates of sensitivity and specificity [15].

PET/CT specificity has been shown to be less than $80 \%$ and $70 \%$ when detecting abdominal and pelvic lesions respectively. Furthermore, it has also been suggested that PET/CT is unable to depict small-volume disease (lesions 5 to $7 \mathrm{~mm}$ in size) and miliary or diffuse peritoneal involvement [13]. This mismatch needs to be considered when approaching SCR because according to Chi et al. [3], this surgical procedure should not be recommended in the presence of peritoneal carcinomatosis in platinumresistant or partially-sensitive ovarian cancer. Thus, one can speculate that in our patient, a higher accuracy of radiological assessment would probably have spared an unnecessary surgical procedure.

\section{Conclusions}

This case suggests that the occurrence of granuloma from a foreign body can induce false-positive imaging of recurrence. Hence, clinical details on previous surgical procedures are necessary for adequate interpretation. Although PET/CT is a useful innovative diagnostic modality in finding neoplastic lesions such as recurrence of ovarian cancer, it is still burdened by false positives and low sensitivity, as demonstrated in the present case. It could fail to identify early small cancer lesions so that CA- 125 remains the most accurate and sensible tool to gain an early prediction of recurrence of disease.

Any imaging modality only increases the detection of recurrence but cannot be considered definitive. It is recommended to double check such cases to confirm or reject the diagnosis.

\section{Consent}

Written informed consent was obtained from the patient for publication of this case report and accompanying images. A copy of the written consent is available for review by the Editor-in-Chief of this journal.

\section{Abbreviations}

CA: Carbohydrate antigen; CT: Computed tomography; F-FDG:

${ }^{18}$ F-fluorodeoxyglucose; PET: Positron emission tomography;

ROC: Recurrent ovarian cancer; SCR: Secondary cytoreductive surgery;

SUV: Standardized uptake value.

\section{Competing interests}

The authors have stated explicitly that there are no competing interests in connection with this article.

\section{Authors' contributions}

$\mathrm{LI}$ and $\mathrm{CM}$ analyzed and interpreted the patient data regarding the cancer disease and the surgery. $\mathrm{LI}$ and $\mathrm{CM}$ were major contributors in writing the manuscript. LS participated in the design of the study and helped to draft the manuscript. RI participated in the design of the study and helped to draft the manuscript. CB participated in the design of the study and helped to draft the manuscript. LV, LDF and EB participated in the design of the study and helped to draft the manuscript. AM participated in the design of the study and helped to draft the manuscript. IP and PP conceived of the study, and participated in its coordination. PBP conceived of the study, and participated in its coordination. All authors read and approved the final manuscript

Received: 30 January 2014 Accepted: 22 April 2014

Published: 18 June 2014

\section{References}

1. Güth U, Huang DJ, Bauer G, Stieger M, Wight E, Singer G: Metastatic patterns at autopsy in patients with ovarian carcinoma. Cancer 2007, 110:1272-1280.

2. Park CM, Kim SH, Kim SH, Moon MH, Kim KW, Choi HJ: Recurrent ovarian malignancy: patterns and spectrum of imaging findings. Abdom Imaging 2003, 28:404-415.

3. Chi DS, McCaughty K, Diaz JP, Huh J, Schwabenbauer S, Hummer AJ, Venkatraman ES, Aghajanian C, Sonoda Y, Abu-Rustum NR, Barakat RR: Guidelines and selection criteria for secondary cytoreductive surgery in patients with recurrent, platinum-sensitive epithelial ovarian carcinoma. Cancer 2006, 106:1933-1939.

4. Pisano C, Bruni GS, Facchini G, Marchetti C, Pignata S: Treatment of recurrent epithelial ovarian cancer. Ther Clin Risk Manag 2009, 5:421-426.

5. Lim JW, Tang CL, Keng GH: False positive F-18 fluorodeoxyglucose combined PET/CT scans from suture granuloma and chronic inflammation: report of two cases and review of literature. Ann Acad Med Singapore 2005, 34:457-460

6. Yüksel M, Akgül AG, Evman S, Batirel HF: Suture and stapler granulomas: a word of caution. Eur J Cardiothorac Surg 2007, 31:563-565. 
7. Kikuchi M, Nakamoto Y, Shinohara S, Fujiwara K, Tona Y, Yamazaki H, Kanazawa $Y$, Kurihara $R$, Imai $Y$, Naito $Y$ : Suture granuloma showing false-positive finding on PET/CT after head and neck cancer surgery. Auris Nasus Larynx 2012, 39:94-97.

8. Benedetti Panici P, De Vivo A, Bellati F, Manci N, Perniola G, Basile S, Muzii L, Angioli R: Secondary cytoreductive surgery in patients with platinum-sensitive recurrent ovarian cancer. Ann Surg Oncol 2007, 14:1136-1142.

9. De laco P, Musto A, Orazi L, Zamagni C, Rosati M, Allegri V, Cacciari N, Al-Nahhas A, Rubello D, Venturoli S, Fanti S: FDG-PET/CT in advanced ovarian cancer staging: value and pitfalls in detecting lesions in different abdominal and pelvic quadrants compared with laparoscopy. Eur $J$ Radiol 2011, 80:98-103.

10. Aletti GD, Dowdy SC, Podratz KC, Cliby WA: Surgical treatment of diaphragm disease correlates with improved survival in optimally debulked advanced stage ovarian cancer. Gynecol Oncol 2006, 100:283-287.

11. Chi DS, Zivanovic O, Levinson KL, Kolev V, Huh J, Dottino J, Gardner GJ, Leitao MM Jr, Levine DA, Sonoda Y, Abu-Rustum NR, Brown CL, Barakat RR: The incidence of major complications after the performance of extensive upper abdominal surgical procedures during primary cytoreduction of advanced ovarian, tubal, and peritoneal carcinomas. Gynecol Oncol 2010, 119:38-42.

12. Kim HS, Chung TS, Suh SH, Kim SY: MR imaging findings of paravertebral gossypiboma. AJNR Am J Neuroradiol 2007, 28:709-713.

13. Prakash P, Cronin CG, Blake MA: Role of PET/CT in ovarian cancer. AJR Am J Roentgenol 2010, 194:464-470.

14. Son H, Khan SM, Rahaman J, Cameron KL, Prasad-Hayes M, Chuang L, Machac J, Heiba S, Kostakoglu L: Role of FDG PET/CT in staging of recurrent ovarian cancer. Radiographics 2011, 31:569-583.

15. Chung HH, Kang WJ, Kim JW, Park NH, Song YS, Chung JK, Kang SB, Lee HP: Role of $\left[{ }^{18} \mathrm{~F}\right] \mathrm{FDG}$ PET/CT in the assessment of suspected recurrent ovarian cancer: correlation with clinical or histological findings. Eur J NuCl Med Mol Imaging 2007, 34:480-486.

doi:10.1186/1752-1947-8-202

Cite this article as: Imperiale et al:: Nonabsorbable suture granuloma mimicking ovarian cancer recurrence at combined positron emission tomography/computed tomography evaluation: a case report. Journal of Medical Case Reports 2014 8:202

\section{Submit your next manuscript to BioMed Central and take full advantage of:}

- Convenient online submission

- Thorough peer review

- No space constraints or color figure charges

- Immediate publication on acceptance

- Inclusion in PubMed, CAS, Scopus and Google Scholar

- Research which is freely available for redistribution 